InVisible Culture • Issue 33: After Douglas Crimp

\title{
After Douglas Crimp \\ Questionnaire Response: TT Takemoto
}

\section{TT Takemoto}

Published on: Jan 05, 2022

DOI: $10.47761 / 494 a 02 f 6.1 \mathrm{dfcf9} 9 \mathrm{~d}$

License: Creative Commons Attribution 4.0 International License(CC-BY 4.0). 
A memorable assertion from Douglas Crimp:

"Of course, everyone knows that the most difficult sport at the Olympics is synchronized swimming."

TT Takemoto is Dean of Humanities and Sciences at California College of the Arts and was Crimp's VCS student and advisee from 1993 to 2002.

Click here to return to the other questionnaire responses. 